\title{
Determinants of leptospirosis in Sri Lanka: Study Protocol
}

Suneth B Agampodi $i^{*}$, Dhanaseela B Nugegoda', Vasanthi Thevanesam²

\begin{abstract}
Background: Leptospirosis is becoming a major public health threat in Sri Lanka as well as in other countries. We designed a case control study to determine the factors associated with local transmission of leptospirosis in Sri Lanka, in order to identify major modifiable determinants of leptospirosis. The purpose of this paper is to describe the study protocol in detail prior to the publishing of the study results, so that the readership will be able to understand and interpret the study results effectively.

Methods: A hospital based partially matched case control design is proposed. The study will be conducted in three selected leptospirosis endemic districts in central Sri Lanka. Case selection will include screening all acute fever patients admitted to selected wards to select probable cases of leptospirosis and case confirmation using an array of standard laboratory criteria. Age and sex matched group of acute fever patients with other confirmed diagnosis will be used as controls. Case to control ratio will be 1:2. A minimum sample of 144 cases is required to detect 20\% exposure with 95\% two sided confidence level and 80\% power. A pre tested interviewer administered structured questionnaire will be used to collect data from participants. Variables included in the proposed study will be evaluated using conceptual hierarch of variables in three levels; Exposure variables as proximal; reservoir and environmental variables as intermediate; socio-demographic variables as distal. This conceptual hierarch hypothesised that the distal and intermediate variables are mediated through the proximal variables but not directly. A logistic regression model will be used to analyse the probable determinants of leptospirosis. This model will evaluate the effect of same level and upper level variables on the outcome leptospirosis, using three blocks.
\end{abstract}

Discussion: The present national control programme of leptospirosis is hampered by lack of baseline data on leptospirosis disease transmission. The present study will be able to provide these essential information for formulation of better control strategies.

\section{Background}

Leptospirosis is thought to be the most widespread zoonotic disease in the world[1]. It poses a major public health threat to the developing and the developed world as an emerging infectious disease. Tens of millions of people are estimated to be affected annually,[2] resulting in 350,000 to 500,000 cases of severe disease[3]. The disease is endemic in humid, tropical, and subtropical areas of the world where most of the developing countries are located[4]. In Asia Pacific region, Latin America and in Southeast Asia, it is highly prevalent[5] and there has been a marked increase in the number of outbreaks

\footnotetext{
* Correspondence: sunethagampodi@yahoo.com

'Department of Community Medicine, Faculty of Medicine and Allied

Sciences, Rajarata University of Sri Lanka

Full list of author information is available at the end of the article
}

and cases reported during the last two decades. Even though the disease is mostly endemic in rural settings, [6] an increasing number of cases and frequent outbreaks among urban dwellers[7,8] is a recent finding worldwide.

The first confirmed case of leptospirosis was reported in Sri Lanka in 1959[9]. Since then, series of confirmed cases were reported from Gampaha, Kegalle, Ratnapura, and Colombo districts during the 1960's and 70's. Disease notification data shows a steady increase in reporting of leptospirosis over the last two decades in Sri Lanka[10]. This may be either due to emerging disease or due to improved surveillance or both. In 2007, clustering of unidentified fever cases and few deaths were reported from Matara, Gampaha and Kandy district and some of these cases were later confirmed as leptospirosis. During 2008, 
Sri Lanka experienced the largest ever outbreak of leptospirosis in its history with 7406 reported cases[11].

Despite the fact that the Epidemiology Unit of Sri Lanka predicted the 2008 outbreak correctly, the public health system was unable to control the massive outbreak due to a scarcity of data. Previously, we reviewed leptospirosis in Sri Lanka and explained the need for confirmation of this outbreak through laboratory confirmation and the importance of investigating this probable leptospirosis outbreak[12]. However, studies on the epidemiology and determinants of local disease transmission are lacking, whereas clinical manifestations are discussed in several papers[13-15].

The global literature contains an extensive data base on the epidemiology of leptospirosis. Most of these studies are retrospective, cross sectional descriptive analysis of cases presenting during a specified time frame. Analytical studies provide the best epidemiological tools in determination and quantifying risk associations. Case control studies are used in this type of diseases, because they are cheap, rapid and easy to conduct. Cohort studies are unrealistic because of very low incidence rates necessitating a very large study sample, which is not cost effective. Analyses of risk factors of leptospirosis have been attempted using case control methodology in several studies[16-25]. Retrospective and prospective studies are available and some studies are based on cases identified through cross sectional antibody prevalence studies. Summary of published case control studies of leptospirosis and identified risk factors are summarized in Table 1.

As leptospirosis is becoming a major public health threat in Sri Lanka, and data on local dynamics of disease transmission is lacking, we designed a case control study to determine the factors associated with local transmission of leptospirosis in Sri Lanka. The study protocol was reviewed and approved by the Board of Study in Community Medicine, Post Graduate Institute of Medicine, Sri Lanka and Ethical Review Committee, Faculty of Medicine, University of Peradeniya, Sri Lanka. The study was conducted during the peak of the 2008 outbreak. The purpose of this paper is to describe the study protocol in detail prior to the publishing of the study results, so that the readership will be able to understand and interpret the study results effectively.

\section{Methods}

\section{Study design}

This is a hospital based case control study.

\section{Study settings}

This study will be conducted in the districts of Kegalle, Kandy, and Matale, in Sri Lanka. These three districts are adjoining districts in the central part of the country
(Figure 1). The Kegalle district is situated in the Sabaragamuwa province and the other two districts are in the Central province. All three districts have been declared as leptospirosis endemic districts in Sri Lanka. Some selected demographic and socio-economic indicators of these three districts are listed in Table 2.

According to routinely reported data, the Kegalle district had one of the highest incidence of leptospirosis in Sri Lanka during the last five years. Kandy and Matale districts show steadily increasing number of reported cases during the same period which was also seen during the present study period. All three districts reported the highest number of cases in the history of Sri Lanka during 2008. Matale district had the highest incidence of leptospirosis in Sri Lanka during the 2008 outbreak.

Three main hospitals in these three selected districts were selected for the present study. All three hospitals are tertiary care units and sentinel sites selected for leptospirosis surveillance by the Epidemiology Unit. Hospitals selected for the present study are listed below.
1. District General Hospital-Kegalle (DGHK)
2. Teaching hospital - Kandy (THK)
3. District General Hospital - Matale (DGHM)

\section{Study population}

The study population will include all clinically suspected leptospirosis patients who will be admitted to the medical wards in the selected government hospitals during the study period. Patients in the paediatric age group will not be included because the study needs invasive procedure (acute and convalescent venous blood sampling) with follow-up which will be difficult for children as well as for parents.. In addition, data on exposure, which will be the main determinant, will be difficult to obtain from paediatric age group. Obtaining data from parents on exposure will not be reliable and comparable to adult patients.

\section{Study sample \\ Cases}

Cases for the present study will be selected after a screening process and confirmatory tests. Recruiting cases will be done prospectively. All fever cases admitted to selected wards will initially be screened using the following inclusion criteria.

1. Patients admitted to medical wards in the selected hospitals

2. Presenting complaint - acute febrile illness (fever less than 15 days and temperature $>37.8^{\circ} \mathrm{C}$ )

3. One of the following major symptoms:

- Headache 
Table 1 Risk factors for human leptospirosis based on case control studies

\begin{tabular}{|c|c|c|c|c|c|}
\hline Authors & Country & Study & $\begin{array}{l}\text { Sample } \\
\text { size }\end{array}$ & Risk factors & Odds ratio(Cl) \\
\hline \multirow[t]{4}{*}{ Douglin et al (1997) } & St. Andrew Barbados & $\begin{array}{l}\text { Laboratory based } \\
\text { retrospective }\end{array}$ & Cases 22 & Gardening & $4.57(1.09-20.36)$ \\
\hline & & & Con. 38 & presence of dogs around the home & $7.82(1.79-46.55)$ \\
\hline & & & & wearing boots in the garden or yard & $8.59(1.93-42.55)$ \\
\hline & & & & walking through ponds or stagnant water & $\begin{array}{l}25.62(2.89- \\
1151.84)\end{array}$ \\
\hline \multirow[t]{8}{*}{ Bovet et al (1999) } & Seychellus & $\begin{array}{l}\text { Population based } \\
\text { prospective }\end{array}$ & Cases 75 & Gardening & $9.86(2.6-36.1)$ \\
\hline & & & Con. 65 & Indoor occupation & $0.28(0.09-0.85)$ \\
\hline & & & & Home built with corrugated iron & $4.6(1.09-19.4)$ \\
\hline & & & & Wet soil around home & $5.65(1.39-23)$ \\
\hline & & & & Refuse not collected by public service & $5.23(1.37-20)$ \\
\hline & & & & Cats at home & $7.55(2.04-27.9)$ \\
\hline & & & & Skin wounds & $6.66(2.04-27.9)$ \\
\hline & & & & Drinking locally made brew & $5.41(1.38-21.2)$ \\
\hline \multirow[t]{3}{*}{$\begin{array}{l}\text { Leal-Castellanos et al } \\
\text { (2003) }\end{array}$} & Chiapas, Mexico & $\begin{array}{l}\text { Rural community } \\
\text { prevalence study }\end{array}$ & $\begin{array}{l}1169 \\
\text { subjects }\end{array}$ & skin cut or abrasion & $4.2(3.1-5.7)$ \\
\hline & & & & contact with animal excreta with no & $1.9(1.3-2.7)$ \\
\hline & & & & protection and with a skin cut or abrasion & $2.3(1.1-4.6)$ \\
\hline \multirow[t]{2}{*}{ Phraisuwan et al (2002) } & Thailand & $\begin{array}{l}\text { High risk exposure } \\
\text { - after pond } \\
\text { cleaning }\end{array}$ & Cases 43 & wearing long pants or skirts & 0.217 \\
\hline & & & Con. 61 & $\begin{array}{l}\text { presence of more than two wounds on the } \\
\text { body }\end{array}$ & 3.97 \\
\hline \multirow[t]{4}{*}{ Ashford et al (2000) } & Nicaragua & $\begin{array}{l}\text { High risk exposure } \\
\text { Following an } \\
\text { Outbreak }\end{array}$ & Case 85 & Rural household & $2.61(1.06-6.45)$ \\
\hline & & & Con. 481 & Gathering wood & $2.08(1.14-3.79)$ \\
\hline & & & & Shelling/husking corn & $1.8(0.72-4.51)$ \\
\hline & & & & Indoor water source & $0.42(0.22-0.80)$ \\
\hline Everard et al & Barbados & $\begin{array}{l}\text { Laboratory based } \\
\text { retrospective }\end{array}$ & & Sugar-cane workers & 5 \\
\hline \multirow[t]{2}{*}{ (1990) } & & & & those whose families minded livestock & 2.5 \\
\hline & & & & rodents in their garden/yard & 1.8 \\
\hline Johnson et al (2004) & Peru & $\begin{array}{l}\text { Endemic area } \\
\text { seroprevalence }\end{array}$ & $\begin{array}{l}\text { Case } 235 \\
\text { Con. } 1116\end{array}$ & Not wearing shoes in the field & $2.17(1.39-3.37)$ \\
\hline \multirow[t]{2}{*}{ Tangkanakul et al (2000) } & $\begin{array}{l}\text { North- eastern, } \\
\text { Thailand }\end{array}$ & $\begin{array}{l}\text { Hospital based } \\
\text { Prospective }\end{array}$ & Case 56 & travel on potholed roads & $5.0(1.2-20.2)$ \\
\hline & & & Con. 145 & traveling by car & $0.2(0.06-0.9)$ \\
\hline \multirow[t]{12}{*}{ Sarkar et al (2002) } & Salvador, Brazil & $\begin{array}{l}\text { During an } \\
\text { epidemic } \\
\text { retrospective } \\
\text { population based }\end{array}$ & Case 101 & Open sewer in proximity & $5.07(2.04-12.64)$ \\
\hline & & & Con. 125 & Open sewer floods during rainy season & $4.21(1.51-12.83)$ \\
\hline & & & & Street floods during rainy season & $2.54(1.08-6.17)$ \\
\hline & & & & $>6$ h/day outdoors & $2.42(1.16-5.00)$ \\
\hline & & & & Contact with sewer water & $3.63(1.69-7.25)$ \\
\hline & & & & Contact with floodwater & $3.03(1.44-6.39)$ \\
\hline & & & & Contact with mud & $3.08(1.32-5.87)$ \\
\hline & & & & Sighting groups of five or more rats & $5.00(2.22-21.25)$ \\
\hline & & & & Peri-domiciliar sighting of rats Sighting & $3.40(1.74-11.78)$ \\
\hline & & & & Sighting rats at work site & $2.40(1.11-5.17)$ \\
\hline & & & & Dog as domestic animal & $1.19(0.57-2.47)$ \\
\hline & & & & Works > 40 h/week & $1.72(0.89-3.66)$ \\
\hline
\end{tabular}


Table 1: Risk factors for human leptospirosis based on case control studies (Continued)

\begin{tabular}{|c|c|c|c|c|c|}
\hline & & & & Works outdoors exclusively & $2.46(1.04-5.11)$ \\
\hline & & & & Work-related contact with trash & $2.36(1.23-5.56)$ \\
\hline \multirow[t]{4}{*}{ Nardone et al (1998) } & Metropolitan France & $\begin{array}{l}\text { Retrospective, } \\
\text { hospital-based }\end{array}$ & Case 90 & Skin lesion & $7.0(2.7-17.6)$ \\
\hline & & & Con. 169 & Countryside residence & $2.9(1.1-7.6)$ \\
\hline & & & & Canoeing & $15.5(1.6-147.0)$ \\
\hline & & & & Any animal contact & $4.8(1.4-16.2)$ \\
\hline
\end{tabular}

- Myalgia

- Prostration

4. Associated with any of the following signs (at least one):

- Conjunctival suffusion/conjunctival

haemorrhage

- Meningeal irritation

- Anuria or oliguria/proteinuria/haematuria

- Jaundice

- Haemorrhages

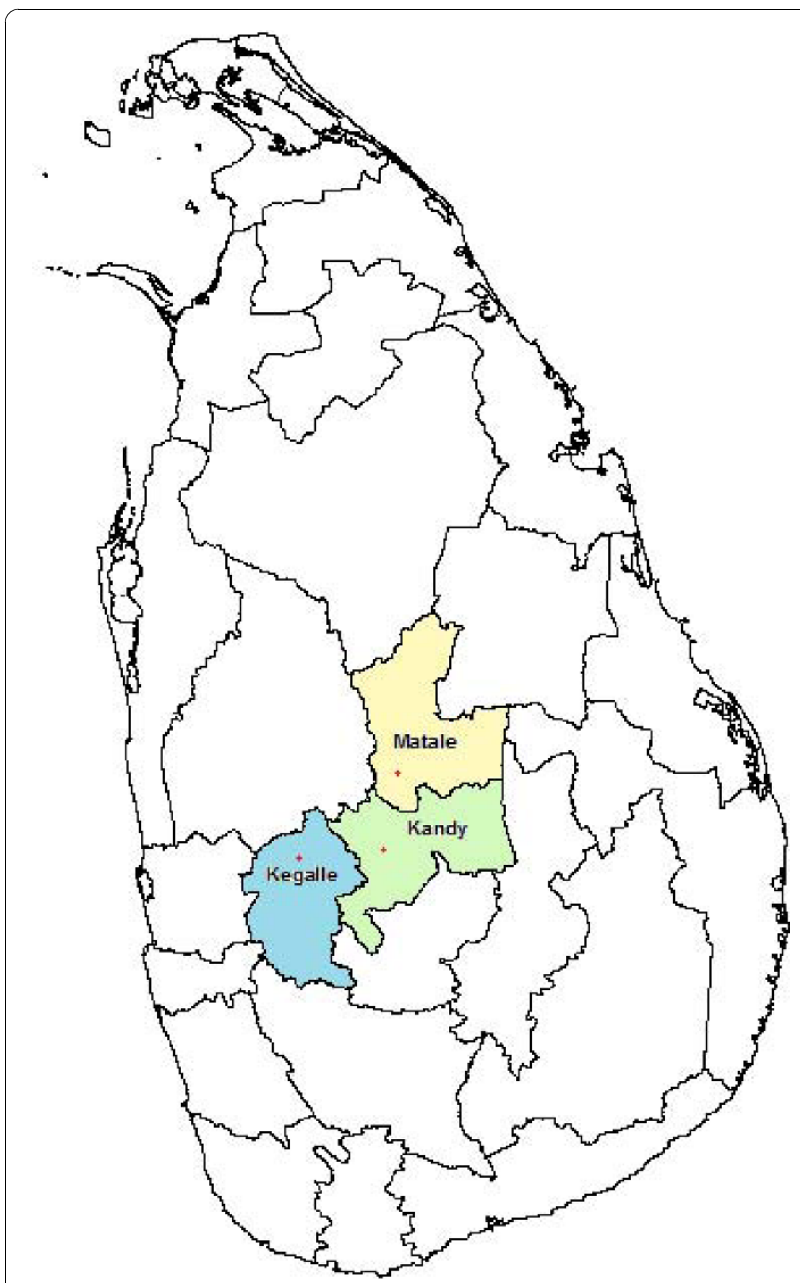

Figure 1 Map of Sri Lanka showing the study area.
- Purpuric skin rash

- Cardiac arrhythmia or failure

These inclusion criteria were formulated after an extensive review of literature. The surveillance case definitions used in Sri Lanka by the national surveillance programme[10] as well as case definitions used in other countries were taken into consideration [26-37]. However, the suggested case definitions in other countries and the surveillance case definition in Sri Lanka seemed too stringent for the initial screening. Hence, the case definitions were modified with the help of two experts (A clinician and microbiologist) to increase the yield of the screening, so that mild to moderate cases would also be included in the selected study sample.

The second step of case selection will be the confirmation of screen positives. In Sri Lanka, recommended leptospirosis diagnostic facilities are not available. The available genus specific MAT performed at the Medical Research Institute (MRI), Colombo is recommended when no other options are available. This genus specific test uses the patoc strain, which belongs to a saprophytic, non-pathogenic Leptospira $s p$. This is a highly nonspecific test and is not included in the laboratory criteria for leptospirosis diagnosis. Disease confirmation of all the selected cases based on the gold standard criteria (MAT) will not be possible in the present study due to severe constraint of funds, logistic difficulties and noncompliance of taking follow-up samples. A confirmed case is defined according to the following criteria.

1. Sero-conversion or a significant increase in Leptospira $s p$. agglutination titre;

Table 2 Selected demographic and socio-economic characteristics of the study settings

\begin{tabular}{lccc}
\hline & Kandy & Kegalle & Matale \\
\hline Total population & $1,279,028$ & 785,524 & 441,328 \\
Land area $\left(\mathrm{km}^{2}\right)$ & 1,940 & 1,693 & 1,993 \\
Crude birth rate (per 1000 population) & 22.4 & 11.5 & 16.7 \\
Crude death rate (per 1000 population) & 6.6 & 5.8 & 5 \\
Median per capita income (Rupees) & 16,203 & 13,114 & 14,119 \\
Paddy harvested area (hectares) & 30,752 & 25,070 & 14,598 \\
\hline
\end{tabular}


a. a MAT sero-conversion: negative first sample and a titre of more than 1:100 in the second sample

b. 4-fold rise in titre between acute and convalescent phase samples; OR

2. A single high Leptospira MAT titre greater than or equal to 800 ; OR

3. Positive PCR; OR

4. A clinical case fulfilling stringent surveillance case definition (surveillance case definition proposed by WHO) and having a positive ELISA IgM test

\section{Exclusion criteria}

When the patient is critically ill and the accompanying persons are unable to provide these details, those cases will be excluded from the cases.

\section{Controls}

\section{Inclusion criteria}

Patients admitted to the same wards with a history of fever, but with a confirmed diagnosis of diseases other than leptospirosis will be selected as controls.

1. Patients admitted to medical wards in selected hospitals

2. Presenting complaint - acute febrile illness (fever less than 15 days)

3. Symptoms and signs not suggestive of leptospirosis (not fulfilling the inclusion criteria as probable cases during the first clinical screening)

4. Exclude leptospirosis by ELISA as described in case definition

5. A laboratory confirmed diagnosis other than leptospirosis as a cause for fever

\section{Exclusion criteria}

1. Critically ill patients who were unable to provide a good exposure history

2. Patient whose diagnosis was ambiguous

For each case, two age and sex matched controls will be selected. Age matching will be done within the range of plus or minus five years.

\section{Sample size}

Sample size was calculated to detect association between leptospirosis and exposure with 95\% two sided confidence level and $80 \%$ power. The formula suggested by Fless and used in Open Epi, open source epidemiologic statistical software for public health was used to calculate the sample size.

Out of the variables selected, sample size calculation was based on proximate variables because the conceptual framework hypothesized that distal variables are mediated through proximate variables (see the variables). The lowest exposure rates among exposure variables in normal population were estimated as $10 \%$ and the exposure in the cases were estimated as $20 \%$.

Based on these assumptions, the minimum sample size required was 144 for each group. With adjustment for probable non-respondent rate of $10 \%$, the final sample size required for the study was 158 cases and 316 controls.

\section{Data collectors and training of data collectors}

Data collectors will include PI and MBBS qualified trained pre-intern medical officer. Recruitment of the data collector was done after a screening process and an interview. The selected data collector will undergo a two-day training which had the following general objectives.

Develop specific and general qualities for the role of data collectors

Be made familiar with the study purpose, procedures, and design

This training will thoroughly discuss the entire study process from pre-data collection activities, actual data collection and post data collection activities. The Data collector will be given a comprehensive knowledge of the entire study process.

\section{Data collection instruments}

An interviewer-administered questionnaire will be used to collect data on co-determinants of human leptospirosis. The questionnaire was formulated in English with a translation to Sinhalese. Re-translation of the questionnaire was done to examine the validity of the translated version.

\section{Variables}

\section{Conceptual hierarchical framework of variable categories}

Variables included in the study instrument were identified through extensive literature review and formal discussions with epidemiologists, microbiologists and clinicians involved in leptospirosis disease prevention, control and management.

The study is planned to evaluate the effects of the postulated risk factors for human leptospirosis among hospital admitted patients. These determinants were chosen after an extensive literature review. The selected determinants were grouped into hierarchical categories according to the conceptual framework for determinants of disease causation[38]. This categorization assumes that each set of distal variable influences the level below or the same level and the effect of the distal variable on the disease is mediated through the proximate variables. This conceptual model implies that demographic and socio-economic variables may determine all variables 
being studied (Figure 2). Further, it is assumed that only the distal or parallel variables can confound the effect of each variable. Since, the effects of distal variables are mediated through proximate variables; lower level variables cannot be a confounder for upper level variables.

Factors that can be modifiable and those that can be used for preventive and control strategies were included in the list.

\section{Outcome measure}

The outcome measure will be the odds ratio associated with various exposure risk factors.

\section{Pre-testing of the study instrument}

Pre-testing of the study instrument will be carried out in order to,

- Determine the time length of the interview

- Improve the wording of the questions

- Eliminate unnecessary questions and add new questions

- Test question sequence

- Correct and improve translation

- Identify conceptually vague items

- Formulate or interview aids to facilitate better interviewing

- Check accuracy and adequacy of questionnaire instructions

- Identify interviewers recoding difficulties.

\section{Quality assurance measures}

The quality assurance measures will be directed at controlling bias, the interview technique, the preparation of the fieldwork, the conduct of the study, and finally at the plausibility of the database. Constant and close supervision of data collection will ensure the quality of data. More than $50 \%$ of data collection will be done by direct supervision of the principal investigator. The PI will visit each centre once in three days for direct supervision and during this visit; spot-checking and back checking will be carried out.

After each interview, each data collector will go over the questionnaire and check for consistency, accuracy and completeness of data. Consistency checks will be run during the data entry to improve the quality of data. Range checks as well as skip and fill applications are incorporated in to data entry programme to ensure that encoded responses are within defined limits.

\section{Control of bias}

Bias and confounding factors can affect any observational study, especially in case control studies. Several potential sources of biases were considered and measures will be taken to minimize those.

\section{Recall bias}

Recall bias is the differential recollection of exposure between cases and controls. Study participants in the present study will be patients from the same wards. Laboratory confirmation of the disease status will not be available for patients at the time of data collection which will minimise recall bias in the study. Use of protocols and probing questions and training of data collector will also be done to minimise this bias.

\section{Selection bias}

Several forms of selection bias may occur in this type of hospital based case control studies. Since the study will be conducted during an epidemic period and all medical

First level (Distal variables)

Demographic and Socio-economic characteristics

\section{Second level \\ (Intermediate variables)}

\author{
Third level \\ (Proximal variables)
}

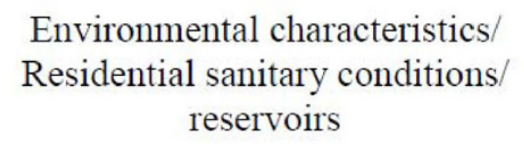

Environmental characteristics/

Residential sanitary conditions/ reservoirs

\section{Exposure to contaminated sources / reservoirs / Behavioural factors}

Figure 2 Hierarchical framework of probable determinants of leptospirosis. 
practitioners are expected to be aware of the paddy field exposure and leptospirosis, there is a possibility that more patients with this specific exposure will be admitted to the hospital. It might overestimate the final effect size. However, selection of fever patients rather than other patients of normal population as controls will minimise this bias. Discussions will be held with all clinicians and OPD doctors and the eligibility criteria will be provided to them to reduce this bias to a minimal level. Selection bias due to hospital selection will occur if the controls are to be selected from the primary study base (general population). It has been suggested that for hospital based case control studies, using controls with similar manifestations will minimise the selection bias [39-41] and present study will follow these guidelines to minimise selection bias.

\section{Interviewer bias}

Interviewer bias is the differential collection of exposure data from cases and controls by the interviewer. To minimise this bias only two interviewers will be used in this study. Both interviewers in the study will not be aware of the final diagnosis at the time of data collection. The clinical picture of study participants' being similar would minimize interviewer bias with the control group. In addition, to minimise this effect, study protocols and highly objective close ended questions will be used in the study.

\section{Confounding factors}

Potential confounding factors for this study include those known socio-demographic factors and environmental factors. Some of the confounding factors will be minimised in the present study using restriction of the study population to adults admitted to particular hospitals. Matching of age and sex for controls will minimise the confounding effect of these known confounders. Details of the other potential confounders will be derived from the questionnaire and multivariate analysis will be used to overcome the effect of these confounding factors.

\section{Quality of data}

To improve the quality of data, following steps will be taken.

- Blinding of the interviewers and patients on the serological diagnosis

- Use of objectively oriented close ended questions as much as possible

- Selecting incidence cases

- Training of data collectors

- Development of protocols and guidelines for data collection and proper supervision by PI

Data processing and analysis

Data will be managed and analyzed using Epi-Info (version 6.04: Centres for Disease Control and Prevention,
Atlanta, GA, USA) and Statistical Package for Social Sciences (version 13.0: SPSS Inc., Chicago, IL, USA) respectively.

All open-ended questions will be coded manually. A codebook is prepared for all open and close-ended questions in the study. The codebook contain the variable names and their labels, the response categories and their labels and codes for missing values. Data will be entered manually as a double entry. During data entry, automatic plausibility controls will be conducted to assure quality of data entry. Descriptive statistics will be computed for demographic variables for both cases and controls.

Analysis of determinants will be done according to the conceptual framework. Bivariate analysis of all determinants and unadjusted odds ratios will be calculated first to provide an overall idea about the probable determinants. In the multivariate analysis, three models will be used. In the first model, proximal variables will be entered to the simple logistic regression model to assess the overall effect of these variables. Odds ratios (ORs) and their corresponding 95\% confidence intervals will be calculated for these variables. In the next model, intermediate level variables will be entered to the model and then proximal level variables will be added to evaluate confounding effects of the intermediate level variables on proximal variables. Remaining effects of proximal level variables that is not mediated through intermediate level variables will be reflected by corresponding OR for proximal level variables. Risk factors significantly $(\mathrm{P}<$ 0.1 ) associated with outcome on each level will be selected for inclusion in to next level. The confounding effects will be detected through change in OR before and after the adjustment for confounding variable. Final set of risk factors are not the results from the full model, which includes all variables, but from the equation corresponding to the level in which the variable is first entered. This will avoid the possibility that the more proximal determinants will remove the explanatory power of more distal determinants. Adjusted ORs with a $\mathrm{p}$ value of $<0.05$ will be interpreted as statistically significant association and $p$ value $>0.05$ and $<0.1$ will be interpreted as having a trend for association.

\section{Ethical considerations}

Each potential respondent will be first provided with an explanation of the purpose, nature time commitment and potential benefits involved in participating in the study, and will be given an assurance of confidentiality. Each prospective participant will be given an opportunity to ask any question regarding the study prior to recruitment and during the study. Participants will be provided with name and address of the principal investigator to contact him any time during the study. Each potential respondent will be free to decline participation 
and/or refuse to answer any specific question without any loss of health care benefits or services. Informed written consent will be obtained from all the patients prior to recruitment.

All data collected in this study will be held in the strictest confidence at all levels. Only the PI will have access to collected data and data sets will bee stored in a secure, password protected computer. The personal data that will be collected will be used for only one purpose; to send investigation reports to the patients.

Ethical clearance for the present study was obtained from the Ethical Review Board of the Faculty of Medicine, University of Peradeniya, Sri Lanka.

\section{Results}

Results of this study will be published in early 2011 .

\section{Discussion}

The present situation of leptospirosis in Sri Lanka is a major concern among public health professionals as well as clinicians. Hence, the need for a national programme of control and prevention of leptospirosis is urgent. However, the preventive and control measures in Sri Lanka are hampered by the lack of those essential baseline data to understand leptospirosis disease dynamics in the population To decide on proper control and preventive measures determinants of local leptospirosis transmission should be clearly defined. During outbreaks, real time data collection is needed for better understanding of disease epidemiology. We discussed here the rationale for the case control study on leptospirosis and the details of the study protocol. If the determinants of leptospirosis could be clearly identified through this study, it will contribute greatly to control and prevention program of leptospirosis in Sri Lanka.

\section{Acknowledgements}

We would like to thank Prof.S.J. Peacock who reviewed and provided valuable advices to improve this protocol. The protocol is approved and cofunded by a WHO research grant through the Epidemiology Unit of Sri Lanka (Grant No. P.O.A. SRL SO1/OWER 1/RER 3/OSER 1/P 2/A-4/FEL) and Oxford-Mahidol Welcome Trust Tropical Medicine Research Institute, Bangkok, Thailand. Laboratory diagnosis was provided free of charge by the Oxford-Mahidol Welcome Trust Tropical Medicine research Institute, Bangkok, Thailand and WHO/FAO/OIE Collaborating Centre for Reference \& research on Leptospirosis, Western Pacific Region, Queensland, Australia. ELISA kits for rapid diagnosis was provided by Inverness Medicals, Australia.

\section{Author details \\ 'Department of Community Medicine, Faculty of Medicine and Allied Sciences, Rajarata University of Sri Lanka. ${ }^{2}$ Department of Microbiology, Faculty of Medicine, University of Peradeniya, Sri Lanka.}

\section{Authors' contributions}

Principal responsibility for the study design, conduct, analysis, interpretation and manuscript preparation was assumed by ASB (MD Community Medicine candidate). NDB, and VT participated in design, supervised the conduct, analysis and interpretation, commented on draft and approved the final protocol.

\section{Competing interests}

The authors declare that they have no competing interests.

Received: 5 November 2010 Accepted: 19 November 2010 Published: 19 November 2010

\section{References}

1. WER: Leptospirosis worldwide, 1999. Wkly Epidemiol Rec 1999, 74:237-242.

2. Cachay ER, Vinetz JM: A global research agenda for leptospirosis. $J$ Postgrad Med 2005, 51:174-178.

3. Hartskeerl RA: Leptospirosis: current status and future trends. Indian J Med Microbiol 2006, 24:309.

4. Brooks FGeo, Butel SJanet, Morse AStephan: Leptospira and leptospirosis. Medical Microbiology. 23 edition. Singapore: MacGrow Hill Education(Asia); 2004, 338-340.

5. Victoriano AF, Smythe LD, Gloriani-Barzaga N, Cavinta LL, Kasai T, Limpakarnjanarat K, Ong BL, Gongal G, Hall J, Coulombe CA, et al: Leptospirosis in the Asia Pacific region. BMC Infect Dis 2009, 9:147.

6. Faine S, Adler B, Bolin C, Perolat P: Epidemiology. Leptospira and Leptospirosis. 2 edition. Melbourne: MediSci; 1999, 70.

7. Gaynor K, Katz AR, Park SY, Nakata M, Clark TA, Effler PV: Leptospirosis on Oahu: an outbreak associated with flooding of a university campus. Am J Trop Med Hyg 2007, 76:882-885.

8. Bharti AR, Nally JE, Ricaldi JN, Matthias MA, Diaz MM, Lovett MA, Levett PN, Gilman RH, Willig MR, Gotuzzo E, Vinetz JM: Leptospirosis: a zoonotic disease of global importance. Lancet Infect Dis 2003, 3:757-771.

9. Rajasuriya K, Somasunderam M, Nagaratnam N: Leptospirosis in Ceylon. J Trop Med Hyg 1959, 62:205-210.

10. Epidemiology Unit: Leptospirosis. Surveillance Case Definitions for Notifiable Diseases in Sri Lanka Colombo: Epidemiology Unit, Ministry of Health; 2005, 19-20.

11. Epidemiological Unit: Selected notifiable diseases reported by Medical Officers of Health. Weekly Epidemiological Report 2009, 36:4.

12. Agampodi S, Peacock SJ, Thevanesam V: The potential emergence of leptospirosis in Sri Lanka. Lancet Infect Dis 2009, 9:524-526.

13. Dassanayake D, Wimalaratna H, Agampodi S, Liyanapathirana V, Piyarathna T, Goonapienuwala B: Evaluation of surveillance case definition in the diagnosis of leptospirosis, using the Microscopic Agglutination Test: a validation study. BMC Infect Dis 2009, 9:48.

14. Kularatne SA: Human leptospirosis: Case studies. Zoonotic \& Emerging Zoonotic Diseases and their Prevention in the SAARC Region Faculty of Veterinary Medicine and Animal Science, University of Peradeniya, Sri Lanka; 2008.

15. Gunawardhana SA, Sellahewa KH: Clinical features of leptospirosis: a prospective descriptive study at the National Hospital of Sri Lanka (NHSL) in 2007. Ceylon Med J 2008, 53:155-156.

16. Ashford DA, Kaiser RM, Spiegel RA, Perkins BA, Weyant RS, Bragg SL, Plikaytis B, Jarquin C, De Lose Reyes JO, Amador JJ: Asymptomatic infection and risk factors for leptospirosis in Nicaragua. Am J Trop Med Hyg 2000, 63:249-254.

17. Bovet $P$, Yersin $C$, Merien $F$, Davis $C E$, Perolat $P$ : Factors associated with clinical leptospirosis: a population-based case-control study in the Seychelles (Indian Ocean). Int J Epidemiol 1999, 28:583-590.

18. Everard CO, Bennett S, Edwards CN, Nicholson GD, Hassell TA, Carrington DG, Everard JD: An investigation of some risk factors for severe leptospirosis on Barbados. J Trop Med Hyg 1992, 95:13-22.

19. Johnson MA, Smith H, Joeph P, Gilman RH, Bautista CT, Campos KJ, Cespedes M, Klatsky P, Vidal C, Terry H, et al: Environmental exposure and leptospirosis, Peru. Emerg Infect Dis 2004, 10:1016-1022.

20. Douglin CP, Jordan C, Rock R, Hurley A, Levett PN: Risk factors for severe leptospirosis in the parish of St. Andrew, Barbados. Emerg Infect Dis 1997, 3:78-80.

21. Leal-Castellanos CB, Garcia-Suarez R, Gonzalez-Figueroa E, Fuentes-Allen JL, Escobedo-de la Penal J: Risk factors and the prevalence of leptospirosis infection in a rural community of Chiapas, Mexico. Epidemiol Infect 2003, 131:1149-1156.

22. Nardone A, Capek I, Baranton G, Campese C, Postic D, Vaillant V, Lienard M, Desenclos JC: Risk factors for leptospirosis in metropolitan France: results of a national case-control study, 1999-2000. Clin Infect Dis 2004, 39:751-753. 
23. Phraisuwan $P$, Whitney EA, Tharmaphornpilas $P$, Guharat $S$, Thongkamsamut $\mathrm{S}$, Aresagig S, Liangphongphanthu J, Junthima K, Sokampang A, Ashford DA: Leptospirosis: skin wounds and control strategies, Thailand, 1999. Emerg Infect Dis 2002, 8:1455-1459.

24. Sarkar U, Nascimento SF, Barbosa R, Martins R, Nuevo H, Kalafanos I, Grunstein I, Flannery B, Dias J, Riley LW, et al: Population-based casecontrol investigation of risk factors for leptospirosis during an urban epidemic. Am J Trop Med Hyg 2002, 66:605-610.

25. Tangkanakul W, Tharmaphornpil P, Plikaytis BD, Bragg S, Poonsuksombat D, Choomkasien P, Kingnate D, Ashford DA: Risk factors associated with leptospirosis in northeastern Thailand, 1998. Am J Trop Med Hyg 2000, 63:204-208.

26. Leptospirosis-response protocol for NSW public health units. NSW Health 2004

27. Alberta Health and Wellness DCaP: Public Health Notifiable Disease Management Guidelines-Leptospirosis. 2005.

28. Diseases ZDNloC: Guidelines for Prevention and Control of Leptospirosis. New Delhi: World Health Organization; 2006.

29. World Health Organization and regional medical research centre: Report of the Brainstorming Meeting on Leptospirosis Prevention and Control. Mumbai 2006.

30. Washington State Department of Health: Leptospirosis. 2002

31. Malasia: Interim guidelines on leptospirosis. 2006.

32. Department of Labour New Zealand: Report on "Opportunities for reduction of the incidence and severity of occupationally acquired leptospirosis in New Zealand. Wellington 2007.

33. John TJ: The prevention and control of human leptospirosis. J Postgrad Med 2005, 51:205-209.

34. Case Definitions: Dengue and Leptospirosis. [http://www.paho.org/]

35. World Health Organization: Human leptospirosis - guidance for diagnosis, surveillance and control. Malta: World Health Organization; 2003, 1-122.

36. Smythe L: PHLN summary laboratory definition. WHO/FAO/OIE Collaborating Centre for Reference \& Research on Leptospirosis, Western Pacific Region.; 2007.

37. Lin CH, Hsieh HF, Yu JC, Hsu SD, Chuang CH, Hsieh CB: Education and imaging. Gastrointestinal: Leptospirosis and abdominal pain. J Gastroenterol Hepatol 2006, 21:1755.

38. Victora CG, Huttly S, Fuchs SC, Olinto MT: The role of conceptual frameworks in epidemiological analysis: a hierarchical approach. Int $J$ Epidemiol 1997, 26:224-227.

39. Wacholder S, Silverman DT, McLaughlin JK, Mandel JS: Selection of controls in case-control studies. II. Types of controls. Am J Epidemiol 1992, 135:1029-1041.

40. Wacholder S, Silverman DT, McLaughlin JK, Mandel JS: Selection of controls in case-control studies. III. Design options. Am J Epidemiol 1992 135:1042-1050.

41. Wacholder S, McLaughlin JK, Silverman DT, Mandel JS: Selection of controls in case-control studies. I. Principles. Am J Epidemiol 1992, 135:1019-1028.

\section{Pre-publication history}

The pre-publication history for this paper can be accessed here: http://www.biomedcentral.com/1471-2334/10/332/prepub

\section{doi:10.1186/1471-2334-10-332}

Cite this article as: Agampodi et al:: Determinants of leptospirosis in Sri Lanka: Study Protocol. BMC Infectious Diseases 2010 10:332.

\section{Submit your next manuscript to BioMed Central and take full advantage of:}

- Convenient online submission

- Thorough peer review

- No space constraints or color figure charges

- Immediate publication on acceptance

- Inclusion in PubMed, CAS, Scopus and Google Scholar

- Research which is freely available for redistribution

Submit your manuscript at www.biomedcentral.com/submit
Biomed Central 